Review

\title{
Antihypertensive Effects of Brazilian Fruits
}

\author{
${ }^{1}$ Augusto Altoé Puppin, ${ }^{2}$ Christiane Mileib Vasconcelos, ${ }^{1}$ Mirian de Almeida Silva, \\ ${ }^{1}$ Ewelyne Miranda Lima, ${ }^{1}$ Tadeu Uggere de Andrade and ${ }^{1}$ Girlandia Alexandre Brasil \\ ${ }^{1}$ Postgraduate Pharmaceutical Sciences Program, University Vila Velha - UVV, Vila Velha, ES - Brazil \\ ${ }^{2}$ Postgraduate Biotechnology Program, University Vila Velha - UVV, Vila Velha, ES - Brazil
}

\author{
Article history \\ Received: 27-03-2020 \\ Revised: 27-04-2020 \\ Accepted: 11-06-2020 \\ Corresponding Author: \\ Girlandia Alexandre Brasil \\ Postgraduate Pharmaceutical \\ Sciences Program, University \\ Vila Velha - UVV, Vila Velha, \\ ES - Brazil \\ Email: gifarmaceutica@gmail.com
}

\begin{abstract}
Cardiovascular disease is a health problem that generates economic and social impacts worldwide and hypertension is a major risk factor for the development of cardiovascular disease. Currently, conventional medicine offers treatments that control and regulate blood pressure through medication, but the traditional medicines of different cultures have used plants and foods to treat and prevent this type of disease for many years. Brazilian flora has enormous potential due to its wide diversity; however, few studies have evaluated the effects of fruits for reducing or preventing hypertension. This literature review was intended to target current work with Brazilian fruits that sought evidence of species for which consumption could serve as an adjuvant to existing drugs for the control of hypertension. We found studies of five Brazilian fruits which some of them are popularly used to treat hypertension and the results of the research were compared and discussed. Schinus terebentifolius, Passiflora edulis, Euterpe oleracea and Insignis platonia demonstrated promising effects, while Myrciaria dubia did not show positive effects. Thus, we can conclude that Brazilian fruit has potential for use in the treatment of hypertension; however, further studies need to be conducted to explore these fruits in order to increase knowledge in this area. Thus, these fruits could be incorporated into food and used as adjuvants in the treatment of this chronic disease, which has negative impacts on the quality of life of the population.
\end{abstract}

Keywords: Blood Pressure, Cardiovascular System, Food, Natural Products

\section{Introduction}

The prevalence of Noncommunicable Diseases (NCDs), such as obesity, type 2 diabetes and Cardiovascular Disease (CD), has grown exponentially worldwide. They can result from a combination of several factors, such as diet, aging, urbanization, smoking and physical inactivity (WHO, 2013; Wild et al., 2004). Among NCDs, CD is the main cause of morbidity and mortality world wide (WHO, 2013).

CD directly influences public health costs and economies of countries, especially developing countries (WHO, 2013). The reason for this is the high costs that arise from the treatment and prevention of $\mathrm{CD}$ and a decrease in personal productivity, which causes an impact in the economy (Stevens et al., 2018). CD is sometimes disabling and leads to increased spending on health services. This has a negative impact on developing countries, where health spending resources are fewer and the population is needier (WHO, 2013). In addition, CD also affects the well-being of individuals and their families, as it is a debilitating disease with associated comorbidities (Malachias et al., 2016; Mozaffarian et al., 2016). In Brazil, it is estimated that the costs and economic losses from this condition exceeds 50 billion of Brazilian reais annually (Stevens et al., 2018).

Hypertension (HA) is one of the major risk factors responsible for the high death rate associated with $\mathrm{CD}$ (Malachias et al., 2016; Mozaffarian et al., 2016). The disease has a multifactorial pathogenesis; it is influenced by genetic and environmental factors that contribute to an imbalance in the homeostasis of the cardiovascular system, leading to the development of hypertension (Whelton et al., 2017).

In addition, environmental factors, such as overweight/obesity, a high-fat diet, excess of sodium intake and alcohol consumption, have large impacts on the development and growth of individuals with $\mathrm{CD}$ worldwide (Bezerra et al., 2018; Samadian et al., 2016). Thus, especially for populations in developing countries, 
where access to modern medicine is difficult, the use of other methods for the treatment or prevention of disease is very important. The use of medicinal plants, as well as dietary interventions using functional foods and nutraceuticals, has been previously investigated and has demonstrated great results (Chen et al., 2014; Magrone et al., 2013; Peluso et al., 2018).

Functional foods are those that provide essential nutrients to the body and also improve general wellbeing or health. It is different of nutraceuticals, that are considered bioactive compounds that generally are not provided as food, but as medicine in the form of capsules or tablets (ANVISA, 1999).

Currently, much is known about the influence of the consumption of functional foods and nutraceuticals in reducing the development of diseases such as cancer, neurological disorders, cardiovascular disease like hypertension, obesity, inflammation and infections (Aune et al., 2017; Avtanski and Poretsky, 2018). In this sense, fruits are an excellent source of nutrients such as carbohydrates, carotenoids, vitamins and minerals, which are essential to the proper functioning of the body (Brookie et al., 2018; Cassidy et al., 2016; Neri-Numa et al., 2018). In addition to these nutrients, fruits contain secondary metabolites such as phenolic acids, anthocyanins and flavonoids that have many beneficial effects on the body (Aune et al., 2017). Thus, by having these qualities, there is a potential for fruits to act as adjuvants in the treatment of various diseases (Dametto et al., 2017; dos Reis et al., 2018; Johnston, 2009; Silva et al., 2016; Vasudevan et al., 2009).

Brazil has a large land area and a great diversity, which is favorable to the discovery of natural products with biological activity (Valli et al., 2018). Also, the traditional medicine produced by Brazilian people has an enormous potential to produce new medicines. Even with the popular use of these plants by people (Akter et al., 2011; dos Santos et al., 2015; Heinrich et al., 2011; Ricardo et al., 2017; Zibadi et al., 2007), only few studies were conducted to evaluate its effects. In this sense, the determination of important biological properties in Brazilian native fruits can help drive consumption, which, along with global dietary management, can contribute to the prevention of $\mathrm{CD}$, including hypertension and other chronic heart-related diseases (Aune et al., 2017; Hügel et al., 2016; NCGC, 2011).

Therefore, the aim of this study was to conduct a literature review of articles published in major scientific databases that have explored the antihypertensive effects of Brazilian fruits.

\section{Methods}

Articles were screened in major databases such as PubMed, ScienceDirect, LILACS, Medline and Scielo using the following indexes: "Brazil", "Fruits" and "Antihypertensive".

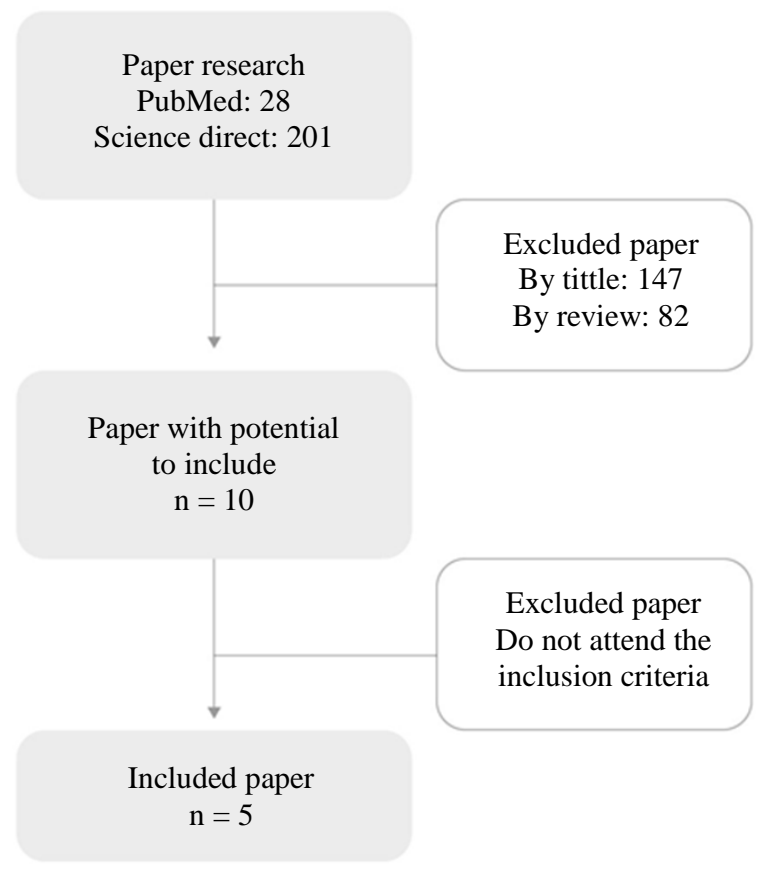

Fig. 1: Flow chart demonstrating the sequence of paper selection and the exclusion of papers for the review

The following inclusion criteria were used: Articles that addressed the antihypertensive effects of Brazilian fruits published between 2008 and 2018. Excluded items included review articles, clinical articles and book chapters (Fig. 1).

\section{Results and Discussion}

In recent years, there has been an increase in interest in how food can affect health. It is known that a balanced and healthy diet is important for maintaining health and preventing disease (D'El-Rei et al., 2016; Mochizuki et al., 2017). Thus, the consumption of processed foods, which is associated with a sedentary lifestyle and other practices, increases the likelihood of the development of chronic diseases such as diabetes and CD, especially Hypertension (HA) (Agosti et al., 2017; Gatineau et al., 2017).

HA is a chronic disease that is closely related to lifestyle and eating habits, such as excessive sodium intake and a sedentary lifestyle (Fig. 2) (Gatineau et al., 2017). Patients with this disease generally take many medications that may have unwanted side effects. Therefore, changes in lifestyle and the addition of foods rich in beneficial compounds, such as polyphenols, can help to control the disease (D'El-Rei et al., 2016).

Thus, foods with certain properties or functional claims, commonly known as functional foods, stand out. These are defined as foods that, when consumed, in addition to the nutritional contributions of macro and 
micronutrients, have other beneficial aspects, such as the presence of compounds that can assist the body in controlling chronic diseases (Agosti et al., 2017; Ahtesh et al., 2018; Cicero and Colletti, 2015; Cicero et al., 2017; Santini et al., 2017). Which is promoted by control and maintenance of the physiological functions of the human body (ANVISA, 1999). However, for these foods to confer benefits, they must be consumed regularly (Santini et al., 2017).

Studies have indicated that the consumption of functional foods can help to control and treat chronic diseases such as HA and these foods could act as adjuvants to drug therapies (Agosti et al., 2017; Arroyo-Johnson and Mincey, 2016; Cicero and Colletti, 2015; D'El-Rei et al., 2016; Johnston, 2009; Santini et al., 2017). Therefore, functional foods can be incorporated into the diet in order to assist in the control of chronic diseases, also traditional people have use it as a medicine to treat diseases (Heinrich et al., 2011; Pereira et al., 2016; Pimenta et al., 2018; Vasquez et al., 2018). Proven and available functional foods include some types of fruits (Santini et al., 2017).

Fruits contain a large number of phenolic molecules, which are produced by secondary metabolism and thanks to their chemical characteristics, have antioxidant properties (Felzenszwalb et al., 2013; Tungmunnithum et al., 2018). Antioxidants are compounds capable of inhibiting or reducing Reactive Oxygen Species (ROS) found in the body, thus reducing the damage caused by them (Cicero and Colletti, 2015). Some people already use fruit for the prevention and treatment of diseases (Da Costa et al., 2017; Poli et al., 2018). In Brazil, this is no different and with the country's rich biome, many fruits may have beneficial effects on chronic diseases, including HA (Felzenszwalb et al., 2013; Gloria et al., 2017; Schulz et al., 2017).

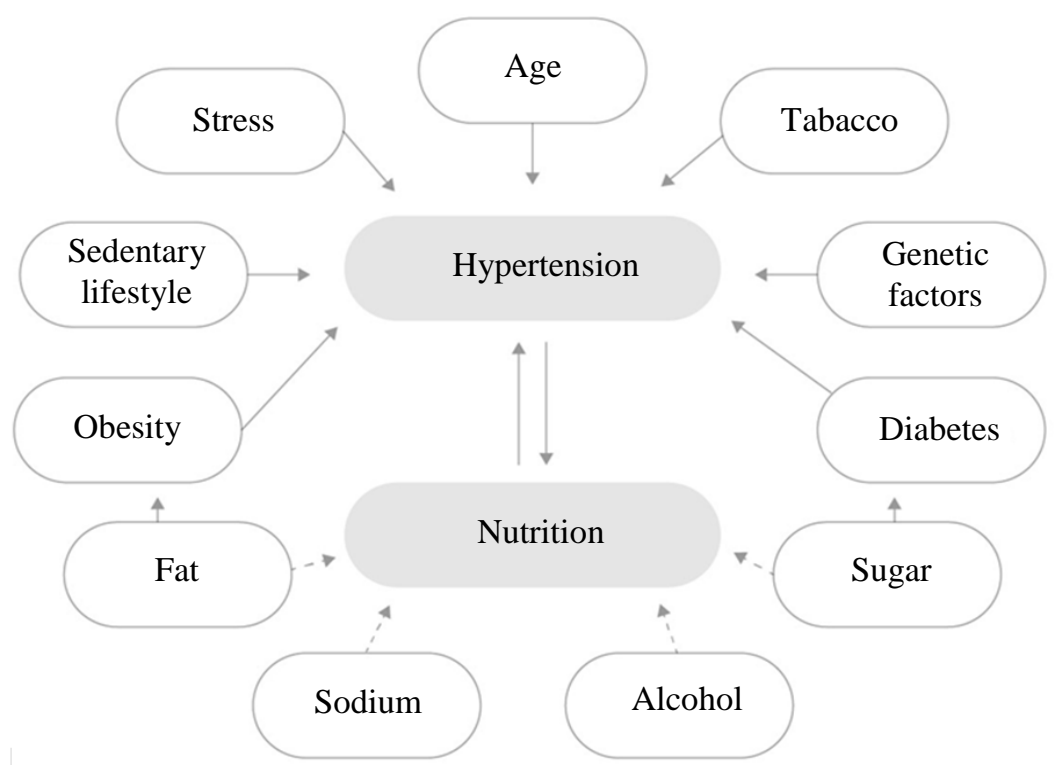

Fig. 2: The multifactorial profile of hypertension. Factors like nutrition, lifestyle, genetic and other diseases help to increase the risk of develop of that disease

Table 1: Summary of main results obtained by papers that study Brazilian fruits as antihypertensive agents

\begin{tabular}{|c|c|c|}
\hline Fruit & Main result & Author/Date \\
\hline Euterpe oleracea mart. & $\begin{array}{l}\text { Extract at a dose of } 200 \mathrm{mg} / \mathrm{kg} \text { promoted decrease on blood pressure } \\
\text { in } 2 \mathrm{~K} 1 \mathrm{C} \text { model of hypertension. Antioxidant effect was show and } \\
\text { treatment promote ameliorate on NO-cGMP pathway. }\end{array}$ & Da Costa et al. $(2012$ \\
\hline Myrciaria dubia Mc. Vaugh & Extract at a dose of $10 \mathrm{mg} / \mathrm{mL}$ did not present $\mathrm{ACE}$ inhibitory activity. & Fujita et al. (2015) \\
\hline $\begin{array}{l}\text { Passiflora edulis Sims } \\
\text { f. Flavicarpa Deg. }\end{array}$ & $\begin{array}{l}\text { Decrease on blood pressure was observed at a dose of } 5,6 \text { and } 8 \mathrm{mg} / \mathrm{kg} \\
\text { in SHR rats after } 5 \text { days of treatment. }\end{array}$ & Konta et al. (2014) \\
\hline Platonia insignis Mart. & $\begin{array}{l}\text { Ethanolic and ethyl acetate extract from fruit peel promote acute } \\
\text { hypotension at } 12.5,25 \text { and } 50 \mathrm{mg} / \mathrm{kg} \text {. }\end{array}$ & Mendes et al. (2014) \\
\hline Schinus terebinthfolius Raddi & $\begin{array}{l}\text { Polyphenols enrich extract at a dose of } 30 \mathrm{mg} / \mathrm{kg} \text { promote decrease in } \\
\text { mean, systolic and diastolic blood pressure. }\end{array}$ & Gloria et al. (2017) \\
\hline
\end{tabular}

2K1C - two kidney one clip. NO-cGMP - Nitric oxide - cyclic guanosine monophosphate. ACE - Angiotensin converting enzyme. SHR - Spontaneously hypertensive rats 
From the research carried out, we found 229 items in the included databases. Taking into account the established criteria, 224 articles were excluded and five species had their antihypertensive properties evaluated: Euterpe oleracea, Myrciaria dubia Mc. Vaughn, Passiflora edulis Sims f. flavicarpa., Insignis platonia Mart and Schinus terebinthifolius. The resume of main results is present at Table 1.

\section{Passiflora edulis Sims $f$. flavicarpa}

The genus Passiflora's belongs to family Passifloraceae and its diverse species have been widely used in traditional medicine in many countries as sedatives, tranquilizers, diuretics and painkillers (Appel et al., 2011; Dhawan et al., 2004; Ngan and Conduit, 2011). Known as passion fruit, it is native to Brazil and is often consumed as fresh fruit pulp and is used as a raw material for juice production (Mercandante et al., 1998). Studies investigating the pharmacological properties of the Passiflora genus have been performed (Appel et al., 2011; Dhawan et al., 2004; Reginatto et al., 2006). Traditionally, Passiflora edulis is indicated to treat anxiety, insomnia, asthma, urinary infections and as a heart tonic (Schotsmans and Fischer, 2011). The antihypertensive effect was demonstrated experimentally, especially for Passiflora edulis bark extract; however, the pulp was also evaluated (Konta et al., 2014; Reginatto et al., 2006; Zibadi et al., 2007).

Konta et al. (2014) evaluated the effects of passion fruit pulp on Spontaneously Hypertensive Rats (SHR), identified the chemical constituents of passion fruit pulp and demonstrated the presence of phenolic compounds, ascorbic acid and carotenoids. This chemistry may be responsible for the beneficial effects observed on the animals' blood pressure.

Some of these compounds, such as quercetin (Duarte et al., 2001) and caffeic acid (Yeh et al., 2009), have been previously associated with antihypertensive action in SHR rats when administered as single compounds and this effect was related to their antioxidant activities.

The antihypertensive effect of Passiflora edulis was evaluated using three different doses $(5,6$ and $8 \mathrm{~g} / \mathrm{kg})$ applied orally over 5 consecutive days. After the treatment period, a decrease in systolic blood pressure was observed at a dose of $8 \mathrm{~g} / \mathrm{kg}$; this reduction was not accompanied by a change in the heart rate. Additionally, renal function and safety of use were evaluated using a micronucleus test. Treatment at the highest dose yielded an increase in the concentration of reduced glutathione $(\mathrm{GSH})$ and a reduction in TBARS levels in the renal tissue, indicating an important antioxidant effect. No toxicity was observed in the micronucleus test. The authors also concluded that the antihypertensive effect of passion fruit pulp can be attributed, at least in part, to the increase in the antioxidant status; however, the precise mechanisms responsible for this action still need further investigation (Konta et al., 2014).

In the cardiovascular system, imbalances in the production of ROS are closely related to the pathophysiology of inflammation, hypertrophy, cell proliferation, apoptosis, angiogenesis and fibrosis (Montezano and Touyz, 2012). The pathogenesis of hypertension appears to be related, at least in part, to excessive oxidative stress, including an increased local oxidative state in the kidneys (Harrison and Gongora, 2009; Kizhakekuttu and Widlansky, 2010).

Studies have linked the antioxidant effects of polyphenols to their ability to reduce blood pressure (Duarte et al., 2001; Hügel et al., 2016; Yeh et al., 2009). Phenolic compounds, through their antioxidant action, improve endothelial function and normalize vascular tone, resulting in an antihypertensive effect (Hügel et al., 2016). Other mechanisms, such as the vasodilator effect of quercetin and the modulation system of gammaaminobutyric acid (Appel et al., 2011), could also contribute to a decrease in blood pressure.

\section{Schinus terebinthifolius Raddi}

Schinus terebinthifolius Raddi (Anacardiaceae) is a plant native to South America that is popularly known as Aroeira or Pimenta Rosa. It is used by people for the treatment of various diseases, which includes antihypertensive, diarrhea, rheumatism and others (Bae et al., 2015; dos Santos et al., 2015).

Gloria et al. (2017) evaluated the effects of in bolus administration of a polyphenols- enriched fraction from Schinus terebinthifolius fruit in normotensive rats. It was observed that the application of the extract provided a significant reduction in the mean arterial, diastolic and systolic pressures, indicating that the fruit would have the potential to reduce blood pressure. However, the extract showed adverse effects through changes in the locomotor activity such as hypolocomotion, muscular incoordination and immobilization that were observed in the treated animals $(30 \mathrm{mg} / \mathrm{kg})$.

The phenolic compounds found in the enriched fraction (naringenin and gallic acid) and other unidentified gallic acid equivalents $(659.21 \pm 05.06 \mathrm{mg} / \mathrm{g})$ are responsible for antioxidant effects through the neutralization of ROS, which contributed to the hypotension that was observed (D'Sousa'Costa et al., 
2015). Thus, Gloria et al. (2017) highlight the importance of quantifying the phenolic compounds and determining the antioxidant activity in all studies investigating fruit because this is an important step towards identifying possible sources of bioactive molecules. In their study, the observed effects were primarily attributed to the two major compounds found (naringenin and gallic acid).

Also, Gloria et al. (2017) concluded that their study provided evidence for the pharmacological potential of Schinus terebinthifolius Raddi fruit extract as antihypertensive and antioxidant, making it a natural fruit source with promise for combating CD.

\section{Myrciaria dubia Mc. Vaughn}

The Myrciaria dubia Mc. Vaughn, popularly known as Camu Camu, Caçari or Araça d'água, is a fruit tree native to the Amazon region in Brazil. The plant can be found in various states in the northern region of Brazil, including Para, Amazon, Roraima, Rondonia and Tocantins. It is widely known to have a high ascorbic acid content (Langley et al., 2015). Because of its rich vitamin $\mathrm{C}$ contend, various studies have shown its neuroprotective, antidyslipidemic, promotes decrease on glucose levels and inflammation (Neri-Numa et al., 2018).

Fujita et al. (2015) evaluated the potential of inhibiting Angiotensin-Converting Enzyme I (ACE) according to a method modified by Kwon et al. (2006) that used rabbit lungs as a substrate. The authors demonstrated the inhibitory effect on ACE at only the highest concentration of the aqueous extract studied $(10 \mathrm{mg} / \mathrm{mL})$; once the dose was too high, the extract was considered ineffective.

Camu Camu has a high concentration of ellagic acid as its main phenolic compound, which could be a reason for the negative result observed. As Kwon et al. (2006) demonstrated, these acids do not have ACE inhibitory activity when tested alone.

Although ACE inhibition was not observed in aqueous extracts of Camu Camu at $10 \mathrm{mg} / \mathrm{ml}$, the author mentioned that further analyses needed to be conducted with high concentrations to confirm the findings (Fujita et al., 2015).

\section{Euterpe oleracea Mart.}

The açai berry, Euterpe oleracea Mart., is a palm species from the Arecaceae family that is cultivated in Brazil because its fruit is a popular food. It is a palm tree native to Brazil and it has small fruits that are round and have a black-purple color. They can be sold frozen or in the form of bottled juice (Yamaguchi et al., 2015).
Additional of its high nutrients contend, traditional population use the berries to treat flu, pain, infections and skin problems (Heinrich et al., 2011). Some other authors has demonstrates that its high phenolic contend can prevent hypertension (Da Costa et al., 2012).

Da Costa et al. (2012) evaluated the effect of a hydro-ethanolic extract of Euterpe oleracea on the development of hypertension using two kidneys, one clip (2K1C) model. The induction of hypertension was observed and chronic treatment at a dose of 200 $\mathrm{mg} / \mathrm{kg} /$ day in drinking water prevented an increase in the systolic blood pressure in the first week of treatment. Additionally, the reduction in the pressure in this group was accompanied by a decrease in renin levels. Moreover, studies in the mesenteric bed demonstrated the reestablishment of vasodilation, promoted by acetylcholine, in these animals (Costa-Júnior et al., 2011).

Chronic treatment also resulted in a reduction in oxidative stress and a decrease in malondialdehyde and carbonylated protein levels in hypertensive treated animals. Furthermore, animals treated with the Euterpe oleracea extract were found to have an increase in antioxidant enzyme activity (SOD, catalase and glutathione). These increase in enzyme activity were combined with an increase in protein expression of SOD1 and 2 and a reduction in NOX and eNOS-4, the latter of which is an important oxidizing enzyme. Together, these data demonstrate the strong antioxidant activity of Euterpe oleracea fruits (Da Costa et al., 2012).

Additionally, previous research performed by Rocha et al. (2007) demonstrated that Euterpe oleracea can promote a vasorelaxant effect at the mesenteric bed, which can be associated with the NO-cGMP pathway and the release of Endothelium-Derived Hyperpolarization Factor (EDHF). Also, Cordeiro et al. (2017) evaluated the effects of chronic treatment with Euterpe oleracea fruit extract $(200 \mathrm{mg} / \mathrm{kg})$ in Spontaneously Hypertensive Rats (SHR) and observed a decrease in the systolic blood pressure and a vasodilatory effect on the mesenteric bed of SHR animals. That effect on pressure was accompanied by a decrease in oxidative stress and an amelioration of histological organization in treated animals.

Thus, all of the studies have together demonstrated that chronic treatment with açai berry extract prevents the development of hypertension, endothelial dysfunction and vascular structural alterations in rats with hypertension. This indicates that the fruit may have potential for use in the treatment of hypertension in humans. 


\section{Platonia insignis Mart.}

Platonia insignis Mart. is popularly known as Bacuri. It belongs to the Clusiaceae family, is native to Brazil and is sourced mainly from the states in the northern of Brazil (Costa-Júnior et al., 2011).

A study performed by Mendes et al. (2014) evaluated the acute hypotensive effects of ethanol extract and ethyl acetate at different doses $(12.5,25$ and $50 \mathrm{mg} / \mathrm{kg}$ ) from Platonia insignis fruit peel in normotensive animals. The study only demonstrated a significant reduction in the mean arterial pressure at doses of 25 and $50 \mathrm{mg} / \mathrm{kg}$ in the ethyl acetate fraction. This was accompanied by hypotension and tachycardia at rates of 12.5 and $25 \mathrm{mg} / \mathrm{kg}$; the latter was also observed for the higher dose $(50 \mathrm{mg} / \mathrm{kg})$.

The analysis of pathways by which the extract caused hypotension involved the co- administration of L-NAME, hexamethonium, verapamil, propranolol and yohimbine. The potentiation of the effect by the co-administration with L-NAME was observed. Moreover, the hypotensive effect was completely abolished by the administration of yohimbine, which indicates that the primary mechanism by which the extract promotes hypotension is via the $\alpha$-adrenergic receptor (Mendes et al., 2014).

Thus, it is possible to conclude that the results are promising, especially considering that few works have evaluated the cardiovascular effects promoted by Platonia insignis. Other studies are important in order to evaluate chronic treatment with fruit, in addition to gaining the ability to determine the compounds responsible for these actions.

\section{Conclusion}

We can conclude that even with the wealth of species found in Brazilian flora, few studies have explored the beneficial effects of its fruits on the cardiovascular system. It was possible to observe the influence of phenolic compounds present in fruits and their promising effects in hypertension, in addition to inferring the mechanisms of these compounds in antioxidant antihypertensive actions (Fig. 3). It is therefore necessary that further studies are conducted in order to enrich the knowledge in this area and to bring forth various fruits with potential use in the prevention and treatment of chronic diseases by acting as functional foods and/or nutraceuticals.

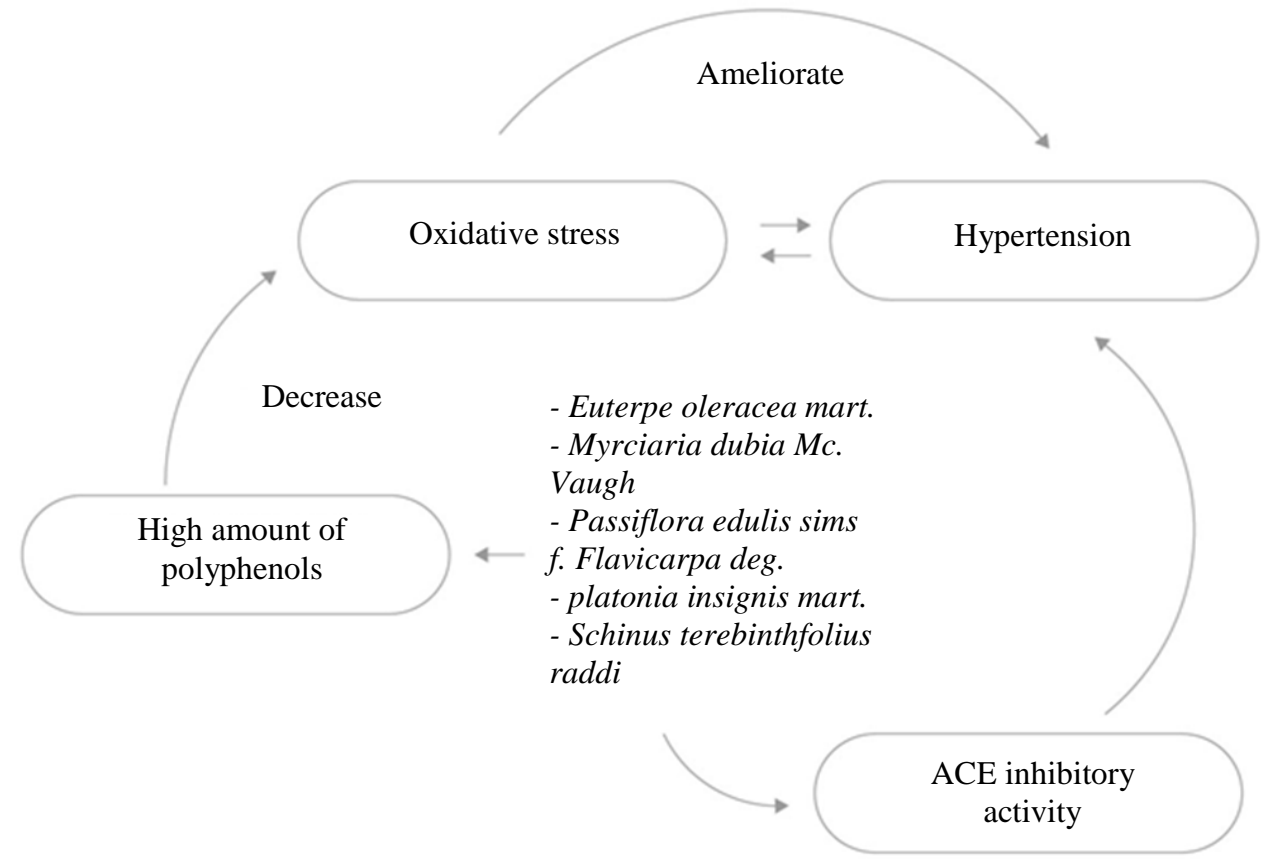

Fig. 3: It is well known the connection between oxidative stress and hypertension. The consume of polyphenols from the Brazilian fruits promote a decrease on oxidative stress, which could help on the decrease of blood pressure observed. That effect are accompanied, in some cases, by the inhibition of angiotensin converting enzyme, which helps to decrease the Renin Angiotensin System (RAS) activation, the main system of blood pressure control and that is augmented in hypertension 


\section{Funding Information}

This research did not receive any specific grant from funding agencies in the public, commercial, or not-forprofit sectors.

\section{Author's Contributions}

Augusto Altoé Puppin: Help with the study design and writing the manuscript.

Christiane Mileib Vasconcelos: Help with the writing of final version of the manuscript.

Mirian de Almeida Silva: Contributed to paper research and with the final version of the manuscript,

Ewelyne Miranda Lima: Contribute with the review of the manuscript, selection of papers and approve the final version of the manuscript.

Tadeu Uggere de Andrade: Contributed with the approval of the final version of the manuscript.

Girlandia Alexandre Brasil: Contributed with the study design, writing the manuscript, approve of final version of the manuscript and paper research.

\section{Ethics}

This article is original and contains unpublished material. The corresponding author confirms that all of the other authors have read and approved the manuscript and no ethical issues involved.

\section{References}

Agosti, M., F. Tandoi, L. Morlacchi and A. Bossi, 2017. Nutritional and metabolic programming during the first thousand days of life. La Pediatria Medica Chirurgica, 39: 57-61. DOI: 10.4081/pmc.2017.157

Ahtesh, F.B., L. Stojanovska and V. Apostolopoulos, 2018. Anti-hypertensive peptides released from milk proteins by probiotics. Maturitas, 115: 103-109. DOI: 10.1016/j.maturitas.2018.06.016

Akter, M.S., S. Oh, J.B. Eun and M. Ahmed, 2011. Nutritional compositions and health promoting phytochemicals of camu-camu (myrciaria dubia) fruit: A review. Food Res. Int., 44: 1728-1732.

DOI: 10.1016/j.foodres.2011.03.045

ANVISA, 1999. Technical regulation establishing the basic guidelines for analysis and verification of functional and or health alleged in food labeling, in the Annex of this Ordinance. DOU - Official Gazette.

Appel, K., T. Rose, B. Fiebich, T. Kammler and C. Hoffmann et al., 2011. Modulation of the g-aminobutyric acid (GABA) system by Passiflora incarnata L. Phytotherapy Res., 25: 838-843.

DOI: $10.1002 /$ ptr.3352
Arroyo-Johnson, C. and K.D. Mincey, 2016. Obesity epidemiology worldwide. Gastroenterol. Clin. North Am., 45: 571-579. DOI: 10.1016/j.gtc.2016.07.012

Aune, D., E. Giovannucci, P. Boffetta, L.T. Fadnes and N.N. Keum et al., 2017. Fruit and vegetable intake and the risk of cardiovascular disease, total cancer and all-cause mortality-A systematic review and dose-response meta-analysis of prospective studies. Int. J. Epidemiol., 46: 1029-1056.

DOI: $10.1093 /$ ije/dyw319

Avtanski, D. and L. Poretsky, 2018. Phyto-polyphenols as potential inhibitors of breast cancer metastasis. Molecular Med., 24: 1-17. DOI: 10.1186/s10020-018-0032-7

Bae, J.W., D.H. Kim, W.W. Lee, H.Y. Kim and C.G. Son, 2015. Characterizing the human equivalent dose of herbal medicines in animal toxicity studies. J. Ethnopharmacol., 162: 1-6. DOI: $10.1016 /$ j.jep.2014.12.023

Bezerra, I.N., N.M.S.G. Bahamonde, D.M.L. Marchioni, D. Chor and L.D.O. Cardoso et al., 2018. Generational differences in dietary pattern among Brazilian adults born between 1934 and 1975: A latent class analysis. Public Health Nutrit., 2: 1-12. DOI: $10.1017 / \mathrm{S} 136898001800191 \mathrm{X}$

Brookie, K.L., G.I. Best and T.S. Conner, 2018. Intake of raw fruits and vegetables is associated with better mental health than intake of processed fruits and vegetables. Frontiers Psychol., 9: 1-14. DOI: $10.3389 /$ fpsyg.2018.00487

Cassidy, A., M. Bertoia, S. Chiuve, A. Flint and J. Forman et al., 2016. Habitual intake of anthocyanins and flavanones and risk of cardiovascular disease in men. Am. J. Clin. Nutrit., 104: 587-594.

DOI: $10.3945 /$ ajen.116.133132

Chen, G., H. Wang, X. Zhang and S.T. Yang, 2014. Nutraceuticals and functional foods in the management of hyperlipidemia. Critical Rev. Food Sci. Nutrit., 54: 1180-1201. DOI: $10.1080 / 10408398.2011 .629354$

Cicero, A.F.G. and A. Colletti, 2015. Nutraceuticals and blood pressure control: Results from clinical trials and meta-analyses. High Blood Pressure Cardiovascular Prevent., 22: 203-213. DOI: $10.1007 / \mathrm{s} 40292-015-0081-8$

Cicero, A.F.G., F. Fogacci and A. Colletti, 2017. Potential role of bioactive peptides in prevention and treatment of chronic diseases: A narrative review. Brit. J. Pharmacol., 174: 1378-1394. DOI: 10.1111/bph.13608

Cordeiro, V.D.S.C., G.F.D. Bem, C.A.D. Costa, I.B. Santos and L.C.R.M.D. Carvalho et al., 2017. Euterpe oleracea Mart. seed extract protects against renal injury in diabetic and spontaneously hypertensive rats: Role of inflammation and oxidative stress. Eur. J. Nutrit. DOI: 10.1007/s00394-016-1371-1 
Costa-Júnior, J.S.D., A.A.C.D. Almeida, A.D.R. Tomé, A.M.D.G.L. Citó and J. Saffi et al., 2011. Evaluation of possible antioxidant and anticonvulsant effects of the ethyl acetate fraction from Platonia insignis Mart. (Bacuri) on epilepsy models. Epilepsy Behav., 22: 678-684.

DOI: 10.1016/j.yebeh.2011.09.021

D'El-Rei, J., A.R. Cunha, M. Trindade and M.F. Neves, 2016. Beneficial effects of dietary nitrate on endothelial function and blood pressure levels. Int. J. Hypertens. DOI: 10.1155/2016/6791519

D'Sousa'Costa, C.O., P.R. Ribeiro, M.B. Loureiro, R.C. Simões and R.D.D. Castro et al., 2015. Phytochemical screening, antioxidant and antibacterial activities of extracts prepared from different tissues of Schinus terebinthifolius Raddi that occurs in the coast of Bahia, Brazil. Pharmacognosy Magazine. DOI: 10.4103/0973-1296.160459

Da Costa, C.A., P.R.B. De Oliveira, G.F. De Bem, L.C.R.M. De Cavalho et al., 2012. Euterpe oleracea Mart.-derived polyphenols prevent endothelial dysfunction and vascular structural changes in renovascular hypertensive rats: Role of oxidative stress. Naunyn-Schmiedeberg's Arch. Pharmacol., 385: 1199-1209. DOI: 10.1007/s00210-012-0798-z

Da Costa, C.A., D.T. Ognibene, V.S.C. Cordeiro, G.F. de Bem and I.B. Santos et al., 2017. Effect of Euterpe oleracea mart. Seeds extract on chronic ischemic renal injury in renovascular hypertensive rats. J. Med. Food. DOI: 10.1089/JMF.2017.0011

Dametto, A.C., D. Agustoni, T.F. Moreira, C.V. Plaza and A.M. Prieto et al., 2017. Chemical composition and in vitro chemoprevention assessment of Eugenia jambolana Lam. (Myrtaceae) fruits and leaves. J. Funct. Foods, 36: 490-502.

DOI: 10.1016/j.jff.2017.07.013

Dhawan, K., S. Dhawan and A. Sharma, 2004. Passiflora: A review update. J. Ethnopharmacol., 94: 1-23. DOI: 10.1016/j.jep.2004.02.023

dos Reis, L.C.R., E.M.P. Facco, M. Salvador, S.H. Flôres and A. de Oliveira Rios, 2018. Antioxidant potential and physicochemical characterization of yellow, purple and orange passion fruit. J. Food Sci. Technol., 55: 2679-2691.

DOI: $10.1007 / \mathrm{s} 13197-018-3190-2$

dos Santos, M.R.G., J.H.S. da Silva and M.L.D.C. Caxito, 2015. Brief review on the medicinal uses and antimicrobial activity of different parts of Schinus terebinthifolius raddi. Int. J. Pharmacy Pharm. Sci., 7: 1-7.

Duarte, J., R. Pérez-Palencia, F. Vargas, M.A. Ocete and F. Pérez-Vizcaino et al., 2001. Antihypertensive effects of the flavonoid quercetin in spontaneously hypertensive rats. Brit. J. Pharmacol., 133: 117-124. DOI: 10.1016/0014-2999(93)90968-n
Felzenszwalb, I., M.R. da Costa Marques, J.L. Mazzei and C.A.F. Aiub, 2013. Toxicological evaluation of Euterpe edulis: A potential superfruit to be considered. Food Chem. Toxicol., 58: 536-544. DOI: $10.1016 /$ j.fct.2013.05.029

Fujita, A., D. Sarkar, S. Wu, E. Kennelly and K. Shetty et al., 2015. Evaluation of phenolic-linked bioactives of camu-camu (Myrciaria dubia Mc. Vaugh) for antihyperglycemia, antihypertension, antimicrobial properties and cellular rejuvenation. Food Res. Int., 77: 194-203. DOI: 10.1016/j.foodres.2015.07.009

Gatineau, E., S. Polakof, D. Dardevet and L. Mosoni, 2017. Similarities and interactions between the ageing process and high chronic intake of added sugars. Nutrit. Res. Rev., 30: 191-207. DOI: $10.1017 / \mathrm{s} 0954422417000051$

Gloria, L.D.L., M.B.D.S. Arantes, S.M.D.F. Pereira, G.D.S. Vieira and C.X. Martins et al., 2017. Phenolic compounds present Schinus terebinthifolius raddi influence the lowering of blood pressure in rats. Molecules. DOI: $10.3390 /$ molecules22101792

Harrison, D.G. and M.C. Gongora, 2009. Oxidative stress and hypertension. Med. Clin. North Am., 93: 621-635. DOI: 10.1007/978-0-387-72347-1_4

Heinrich, M., T. Dhanji and I. Casselman, 2011. Açai (Euterpe oleracea Mart.) - A phytochemical and pharmacological assessment of the species' health claims. Phytochemistry Lett., 4: 10-21. DOI: $10.1016 /$ j.phytol.2010.11.005

Hügel, H.M., N. Jackson, B. May, A.L. Zhang and C.C. Xue, 2016. Polyphenol protection and treatment of hypertension. Phytomedicine, 23: 220-231. DOI: $10.1016 /$ j.phymed.2015.12.012

Johnston, C., 2009. Functional foods as modifiers of cardiovascular disease. Am. J. Lifestyle Med., 3: 39S-43S. DOI: 10.1177/1559827609332320

Kizhakekuttu, T.J. and M.E. Widlansky, 2010. Natural antioxidants and hypertension: Promise and challenges. Cardiovascular Therapeut., 28: 1-21. DOI: 10.1111/j.1755-5922.2010.00137.x.Natural

Konta, E.M., M.R. Almeida, C. Lira, J. Darc and C. Darin et al., 2014. Evaluation of the antihypertensive properties of yellow passion fruit pulp (Passiflora edulis Sims f. fl avicarpa Deg.) in spontaneously hypertensive rats. Phytotherapy Res., 28: 28-32. DOI: $10.1002 /$ ptr.4949

Kwon, Y.I., H.D. Jang and K. Shetty, 2006. Evaluation of Rhodiola crenulata and Rhodiola rosea for management of Type II diabetes and hypertension. Asia Pacific J. Clin. Nutrit., 15: 425-432.

Langley, P.C., J.V. Pergolizzi, R. Taylor and C. Ridgway, 2015. Antioxidant and associated capacities of Cати Cати (Myrciaria dubia): A systematic review. J. Alternative Complementary Med., 21: 8-14. DOI: 10.1089/acm.2014.0130 
Magrone, T., F.P. De Heredia, E. Jirillo, G. Morabito and A. Marcos et al., 2013. Functional foods and nutraceuticals as therapeutic tools for the treatment of diet-related diseases. Canad. J. Physiol. Pharmacol., 396: 387-396.

Malachias, M., W. Souza, F. Plavnik, C. Rodrigues and A. Brandão et al., 2016. 7th Brazilian guidelines for hypertension. Arquivos Brasileiros Cardiologia.

Mendes, M.B., J.C. da Silva-Filho, C.K.B. Sabino, D.D.R. Arcanjo and C.M.M. Sousa et al., 2014. Pharmacological evidence of $\alpha_{2}$-adrenergic receptors in the hypotensive effect of Platonia insignis mart. J. Medicinal Food, 17: 1079-1085. DOI: 10.1089/jmf.2013.0151

Mercandante, A.Z., G. Britton and D.B. RodríguezAmaya, 1998. Carotenoids from yellow passion fruit (Passiflora edulis). J. Agric. Food Chem., 46: 4102-4106. DOI: 10.1021/jf9801724

Mochizuki, K., N. Hariya, K. Honma and T. Goda, 2017. Relationship between epigenetic regulation, dietary habits and the developmental origins of health and disease theory. Congenital Anomalies, 57: 184-190. DOI: $10.1111 /$ cga. 12213

Montezano, A.C. and R.M. Touyz, 2012. Molecular mechanisms of hypertension-reactive oxygen species and antioxidants: A basic science update for the clinician. Canad. J. Cardiol., 28: 288-295.

DOI: 10.1016/j.cjca.2012.01.017

Mozaffarian, D., E.J. Benjamin, A.S. Go, D.K. Arnett and M.J. Blaha et al., 2016. AHA statistical update heart disease and stroke statistics-2016 update a report from the American Heart Association. Circulation, 133: e38-e360.

DOI: $10.1161 /$ CIR.0000000000000350

NCGC, 2011. Hypertension: The clinical management of primary hypertension in Adults: Update of clinical guidelines 18 and 34. Hypertension: The Clinical Management of Primary Hypertension in Adults: Update of Clinical Guidelines 18 and 34, National Clinical Guideline Centre.

Neri-Numa, I.A., R.A. Soriano Sancho, A.P.A. Pereira and G.M. Pastore, 2018. Small Brazilian wild fruits: Nutrients, bioactive compounds, health-promotion properties and commercial interest. Food Res. Int., 103: 345-360. DOI: 10.1016/j.foodres.2017.10.053

Ngan, A. and R. Conduit, 2011. A double - blind, Placebo - controlled investigation of the effects of Passiflora incarnata (Passion flower) herbal tea on subjective sleep quality. Phytoterapy Res., 1159: 1153-1159.

Peluso, I., D.V. Valencia, C.O. Chen and M. Palmery, 2018. Activities of nutraceuticals and functional foods 2018. Oxidative Medicine and Cellular Longevity.
Pereira, T.M.C., F.S. Pimenta, M.L. Porto, M.P. Baldo and B.P. Campagnaro et al., 2016. Coadjuvants in the diabetic complications: Nutraceuticals and drugs with pleiotropic effects. Int. J. Molecular Sci.

DOI: $10.3390 /$ ijms 17081273

Pimenta, F.S., M. Luaces-Regueira, A.M. Ton, B.P. Campagnaro and M. Campos-Toimil et al., 2018. Mechanisms of action of kefir in chronic cardiovascular and metabolic diseases. Cellular Physiol. Biochem., 48: 1901-1914.

DOI: $10.1159 / 000492511$

Poli, A., C.M. Barbagallo, A.F.G. Cicero, A. Corsini and E. Manzato et al., 2018. Nutraceuticals and functional foods for the control of plasma cholesterol levels. An intersociety position paper. Pharmacol. Res., 134: 51-60.

DOI: 10.1016/j.phrs.2018.05.015

Reginatto, F.H., F. De-Paris, R.D. Petry, J. Quevedo and G.G. Ortega et al., 2006. Evaluation of anxiolytic activity of spray dried powders of two south Brazilian Passiflora species. Phytotherapy Res., 20: 348-351. DOI: 10.1002/PTR.1853

Ricardo, L.M., J. De Paula-Souza, A. Andrade and M.G.L. Brandão, 2017. Plants from the Brazilian traditional medicine: Species from the books of the polish physician Piotr Czerniewicz (Pedro Luiz Napoleão Chernoviz, 1812-1881). Brazilian J. Pharm., 27: 388-400.

DOI: 10.1016/j.bjp.2017.01.002

Rocha, A.P.M., L.C.R.M. Carvalho, M.A.V. Sousa, S.V.F. Madeira and P.J.C. Sousa et al., 2007. Endothelium-dependent vasodilator effect of Euterpe oleracea Mart. (Açaí) extracts in mesenteric vascular bed of the rat. Vascular Pharmacol., 46: 97-104. DOI: 10.1016/j.vph.2006.08.411

Samadian, F., N. Dalili and A. Jamalian, 2016. Lifestyle modifications to prevent and control hypertension. Iranian J. Kidney Dis., 10: 237-263. PMID: 27721223

Santini, A., G.C. Tenore and E. Novellino, 2017. Nutraceuticals: A paradigm of proactive medicine. Eur. J. Pharm. Sci., 96: 53-61. DOI: 10.1016/j.ejps.2016.09.003

Schotsmans, W.C. and G. Fischer, 2011. Passion Fruit (Passiflora edulis Sim.). In: Postharvest Biology and Technology of Tropical and Subtropical Fruits, Yahia, E.M. (Ed.), Elsevier, pp: 125-142.

Schulz, M., F.C. Biluca, L.V. Gonzaga, G.D.S.C. Borges and L. Vitali et al., 2017. Bioaccessibility of bioactive compounds and antioxidant potential of juçara fruits (Euterpe edulis Martius) subjected to in vitro gastrointestinal digestion. Food Chem., 228: 447-454. DOI: 10.1016/j.foodchem.2017.02.038 
Silva, R.M., L.D. Pereira, J.H. Véras, C.R. do Vale and L. Chen-Chen et al., 2016. Protective effect and induction of DNA repair by Myrciaria cauliflora seed extract and pedunculagin on cyclophosphamide-induced genotoxicity. Mutat. Res. - Genetic Toxicol. Environ. Mutagenesis, 810: 40-47. DOI: 10.1016/j.mrgentox.2016.10.001

Stevens, B., L. Pezzullo, L. Verdian, J. Tomlinson and A. George et al., 2018. The economic burden of heart conditions in Brazil. Arquivos Brasileiros Cardiologia.

Tungmunnithum, D., A. Thongboonyou, A. Pholboon and A. Yangsabai, 2018. Flavonoids and other phenolic compounds from medicinal plants for pharmaceutical and medical aspects: An overview. Medicines, 5: 93-93.

DOI: 10.3390/medicines5030093

Valli, M., H.M. Russo and V.D.S. Bolzani, 2018. The potential contribution of the natural products from Brazilian biodiversity to bioeconomy. Anais Acad. Brasileira Ciencias, 90: 763-778. DOI: 10.1590/0001-3765201820170653

Vasquez, E.C., S.S. Meyrelles, A.L. Gava, B.P. Campagnaro and J. Gil-longo et al., 2018. Beneficial effects of the synbiotic kefir on the neural control of cardiovascular function. J. Food Microbiol.

Vasudevan, K., R. Malarmagal, H. Charulatha, V.L. Saraswatula and K. Prabakaran, 2009. Larvicidal effects of crude extracts of dried ripened fruits of Piper nigrum against Culex quinquefasciatus larval instars, (June).
Whelton, P.K., R.M. Carey, W.S. Aronow, D.E. Casey et al., 2017. Guideline for the prevention, detection, evaluation and management of high blood pressure in adults: A report of the American College of Cardiology/American Heart Association Task force on clinical practice guidelines. J. Am. Coll. Cardiol.

WHO, 2013. World health day 2013 - hypertension. A Global Brief on Hypertension.

Wild, S., G. Roglic, A. Green, R. Sicree and H. King, 2004. Estimates for the year 2000 and projections for 2030. Diabetes Care, 27: 1047-1053.

Yamaguchi, K.K.D.L., L.F.R. Pereira, C.V. Lamarão, E.S. Lima and V.F. Da Veiga-Junior, 2015. Amazon acai: Chemistry and biological activities: A review. Food Chem., 179: 137-151.

DOI: 10.1016/j.foodchem.2015.01.055

Yeh, C.T., W.H. Huang and G.C. Yen, 2009. Antihypertensive effects of Hsian-tsao and its active compound in spontaneously hypertensive rats. J. Nutrit. Biochem., 20: 866-875. DOI: 10.1016/j.jnutbio.2008.07.015

Zibadi, S., R. Farid, S. Moriguchi, Y. Lu and L.Y. Foo et al., 2007. Oral administration of purple passion fruit peel extract attenuates blood pressure in female spontaneously hypertensive rats and humans. Nutrit. Res., 27: 408-416.

DOI: 10.1016/j.nutres.2007.05.004 